Anales de Literatura Hispanoamericana

ISSN-e: 1988-2351

\title{
Borges y la vanguardia de los años 20: tres libros desterrados
}

\author{
Luis Fuente Pérez ${ }^{1}$
}

Resumen. A la muerte de Jorge Luis Borges reapareció al fin la que podríamos llamar su "obra invisible": tres libros de ensayos de los años 20 cuya reedición prohibió tajantemente en vida. A lo largo de estas páginas nos propondremos indagar en el contexto y los motivos que llevaron a la escritura de estos volúmenes, así como en los temas e intereses que en ellos se entretejen, los cuales serán la simiente de muchas de las cuestiones que fascinen al futuro Borges. De esta forma, buscaremos apreciar la obra borgiana en su continuidad y entender las posibles razones que provocaron el destierro de esos textos de la nómina canónica del argentino hasta su muerte.

Palabras clave: Borges; ensayo; vanguardia; criollismo; nacionalismo.

\section{[en] Borges and the Avant-garde of the 1920's: Three Banished Books}

\begin{abstract}
After Jorge Luis Borges's death, what we could call his 'invisible work' eventually reappeared: three books of essays published in the 1920's whose reedition he categorically banned during his life. Throughout these pages, we will delve into the cultural context of the essays and Borges's reasons for writing them. In addition, we will examine the main topics and interests of the author in these volumes, since many of them are the germ of some fascinating issues of his future writings. Therefore, we will try to deal with Borges's work in its continuity and to understand the possible reasons that led him to banish these texts until his deathding.
\end{abstract}

Keywords: Borges; essay; avant-garde; criollismo; nationalism.

Cómo citar: Fuente Pérez, L. (2020) Borges y la vanguardia de los años 20: tres libros desterrados, en Anales de Literatua Hispanoamericana 49, 353-366.

Every man is a moon and has a side which he turns towards nobody: you have to slip around behind it if you want to see it.

Mark Twain

Sin lugar a dudas Borges es uno de los escritores que más se ha involucrado en la creación y en el moldeo de lo que se conoce como figura de autor, aquello que podemos definir como la imagen y la interpretación que busca transmitir un autor al público en relación a su persona y a su propia obra. Este proceso se ve enmarcado en una situación histórica específica que se extiende hasta nuestros días y en la que Borges supo moverse de forma privilegiada: nos referimos al star system literario nacido desde la internacionalización del llamado boom latinoamericano de los 60. Tanto los escritores jóvenes del boom como sus predecesores y maestros pasaron a engrosar la primera fila del sistema literario. Este salto al estrellato del que se beneficiaron algunos autores hispanoamericanos, sustentado en el acortamiento de las distancias que proporcionó la disminución del tiempo en los viajes intercontinentales y en la mayor exposición que permitían las nuevas tecnologías (sobre todo la televisión), incrementó notablemente el interés global del público-lector en los autores de esas obras que se habían convertido en auténticos best-sellers. Conferencias en los lugares más variados del mundo, platós televisivos, entrevistas de alcance mundial, doctorados honoris causa en prestigiosas universidades, tiradas editoriales de decenas de miles de ejemplares, la figura 
pública del intelectual latinoamericano políticamente involucrado que se forjó tras la Revolución Cubana... Todas estas circunstancias y posibilidades hicieron que el rostro, la voz y las opiniones de ciertos escritores se convirtieran en habituales, sobre todo a lo largo y ancho del territorio de habla hispana e incluso trascendiendo sus fronteras.

En este contexto, pese a tener ya cerca de 70 años y estar completamente ciego, se movió Borges de forma en extremo fluida, siendo su rostro uno de los más repetidos en todos los televisores y alcanzando sus opiniones una gran repercusión. Sin embargo, no solo se involucró a través de la exposición continua, sino que también lo hizo tratando de llevar un férreo control sobre obra, con especial atención en la pretérita.

De esta forma, a través de un modelaje y de un tallado constantes por su parte, se fue creando el personaje, la ficción que fue Jorge Luis Borges en sus años como rostro visible del star system cultural de Occidente $^{2}$. A pesar de todo, el argentino no empezó a escribir en el momento de su ascenso a la fama internacional, sino que tenía ya casi medio siglo de trabajo a sus espaldas cuando este se produjo; con lo cual, a la hora de hacer coincidir la figura de autor que quiso transmitir con su pasado literario, no le quedó más remedio que manipular este último para lograrlo. Los cambios que introdujo en sus primeros libros al iniciar la publicación de sus Obras completas en 1954 son ilustrativos de este hecho (por ejemplo, la progresiva reescritura, casi completa al final, de Fervor de Buenos Aires), y, aún más, la supresión absoluta y la prohibición expresa de reeditar tres volúmenes de ensayos de los años 20. En esos tres libros nos centraremos a lo largo de estas páginas: Inquisiciones (1925), El tamaño de mi esperanza (1926) y El idioma de los argentinos (1928). Así, nuestros objetivos en este estudio consistirán en indagar en el contexto en el que fueron escritos y publicados estos volúmenes, ver las líneas maestras que los estructuran y esbozar una explicación del porqué de su proscripción. En resumen, tratar de ligar esos textos con el posterior Borges y ver el cuadro que queda al hacerlo, el continuum que fue la obra del argentino y que este quiso truncar conscientemente en aras de una interpretación unívoca de su figura.

El retorno de Borges a Buenos Aires se produjo en 1921. Tras su estancia en Suiza y en España, donde entró en contacto con las vanguardias europeas (primero con el expresionismo alemán y luego con los círculos ultraístas españoles en el bando de Cansinos Assens), el joven Borges intentó trasladar estas corrientes al panorama literario de la Argentina ${ }^{3}$. De estas fechas datan sus experiencias ultraístas en revistas como Prisma o Proa, al lado de otros de los grandes nombres de la renovación literaria argentina, tal Oliverio Girondo, Macedonio Fernández o Ricardo Güiraldes. No obstante, Borges empieza a mostrar muy pronto reticencias contra el Ultraísmo e inicia un periodo de indagación que será fundamental para su posterior evolución literaria ${ }^{4}$. Tanto, que autores como Olea Franco consideran que "durante esta etapa se definen los elementos básicos del 'sistema literario' borgeano" (1993: 19). Veremos cómo, en cierta medida, esto es muy cierto. Sin embargo, antes de nada, hay que preguntarse a qué vino este rechazo tan fuerte y brusco de la corriente que nada más desembarcar había tratado de abanderar en el mundo literario porteño. Por supuesto, hubo modificaciones en su concepción de la literatura, pero también fue de capital importancia el contexto socio-histórico de la Argentina y las polémicas discusiones que monopolizaban los círculos culturales e institucionales, a las que Borges se lanzó con entusiasmo. De esta suerte, desde el interés en formalizar una nueva poética cuyo núcleo residiera en una renovación meramente estética ${ }^{5}$, Borges pronto viró hacia una renovación de otro signo, tanto estética como fuertemente ideológica y que orbitó en gran medida en torno a las preocupaciones identitarias y nacionalistas que se estilaron durante aquellos años.

Pero a la hora de entender por qué territorios se mueven las discusiones en la Argentina de los 20, tenemos que retroceder unos años, hasta el sexenio que abarca de 1910 a 1916, y situarnos en una polémica cuyo origen se remonta a principios del XIX. En esa primera fecha se conmemora el Centenario del inicio

\footnotetext{
${ }^{2}$ De lo consciente que fue de esta disociación entre autor-hombre y figura de autor puede dar cuenta una intuición previa expresada en un magnífico texto de El hacedor, anterior cronológicamente a esta época del star system: "Borges y yo".

${ }^{3}$ Un excelente y minucioso análisis de esta época es trazado en el libro de Rafael Olea Franco presente en la bibliografía. También da un panorama muy interesante Beatriz Sarlo en el artículo titulado "Vanguardia y criollismo: La aventura de Martín Fierro".

${ }^{4}$ Señala Borges, ya en Inquisiciones, con respecto al Ultraísmo: "pero también he comprobado que, sin quererlo, hemos incurrido en otra retórica, tan vinculada como las anteriores al prestigio verbal. [...] Bella y triste sorpresa la de sentir que nuestro gesto de entonces, tan espontáneo y fácil, no era sino el comienzo torpe de una liturgia" (1925: 97-98). En su correspondencia de esos primeros años 20 también se muestran estas reservas crecientes.

${ }^{5}$ Pensemos en los preceptos ultraístas, deudores del "Manifiesto" publicado en España en 1918, que aparecieron en la revista Nosotros en 1921
} 
del movimiento de independencia y en la segunda el Centenario de la constitución formal de la República Argentina. Debemos formular, asimismo, dos dicotomías en las cuales encarna esa polémica tan relevante y productiva en toda América Latina: la noción de identidad, construida en la Argentina en torno a las parejas civilización/barbarie y a su posterior revisión progresismo/nacionalismo. La primera dicotomía es la clásica decimonónica, instaurada en el contexto de la conformación territorial definitiva del estado y que será personificada por Borges en la oposición Sarmiento/Rosas. Vive su auge una vez derrotado el enemigo común español, cuando las disputas en el seno de la nación se vuelven hacia dentro, y se cimienta en relación a la organización del territorio. La segunda dicotomía, en cambio, prima en el comienzo del siglo XX, una vez superado el trauma de la construcción nacional física, y juega con otro tipo de premisas.

A lo largo del siglo XIX, se impusieron las tesis positivistas y la noción de progreso se volvió una obsesión para la clase dirigente. En aras de modernizar el país e igualarlo a la élite económica de Occidente, se "importan" millones de inmigrantes europeos blancos, se aborda la construcción de grandes infraestructuras y el desarrollo de un mercado capitalista-exportador, además de tratar de eliminar a las poblaciones indígenas, símbolo del polo de la barbarie. Tras la batalla de Caseros y el fin de las campañas del desierto contra los indios, sucesivos gobiernos oligarcas comandan una época de cierta tranquilidad institucional en la que la noción de progreso marca un camino esperanzador. Por supuesto, este progreso fue más ficticio que real, al menos para la mayor parte de la población. Si a esto le sumamos el fracaso de la noción positivista de progreso, asociado a la decadencia de Occidente que diagnosticara Spengler y que vio una suerte de confirmación en la Primera Guerra Mundial, el sentimiento de afirmación de la identidad nacional que en las décadas anteriores había orbitado en torno a una europeización de la Argentina, toma ahora otros derroteros.

Así, se deja de aspirar a la modernización y cultura europeas y se indaga en la identidad inmanente a la nación argentina ${ }^{6}$. Esta exacerbación del sentimiento nacional se ve reforzada con una circunstancia que ya había sido problemática durante el último tercio del siglo XIX y que ahora, al imponerse este antieuropeísmo, alcanza una importancia aún mayor: el estatus del inmigrante en la Argentina. Tengamos en cuenta que un porcentaje verdaderamente amplio de la población se componía de las diversas oleadas migratorias que se produjeron a finales del XIX y principios del XX. El rechazo de lo ajeno, del inmigrante, y la búsqueda de las esencias trascendentales de la argentinidad coparán el núcleo de las discusiones en torno a la identidad y al proyecto de unidad nacional. Por ello, la oposición criollo/inmigrante será profundamente característica de este periodo, no solo como un sentir popular, sino, como veremos, enarbolada por los círculos intelectuales productores del sentido cultural. ${ }^{7}$

Una vez realizado este imprescindible resumen del contexto socio-histórico que marcó las primeras décadas del siglo XX, valoremos el papel que jugaron los intelectuales en la cuestión nacionalista durante este periodo. Siguiendo a Olea Franco (1993), podemos señalar tres propuestas que buscaron constituir el espíritu unitario de la nación. Por un lado, tenemos la visión hispánica de Manuel Gálvez, que defiende la raíz hispana de la Argentina y promueve la vuelta de sus valores. Por otro, la propuesta de Ricardo Rojas, quien, en libros patrocinados por el Estado (con el colofón de la primera Historia de la literatura argentina), propugna la creación de ese espíritu nacional argentino, asimilando a las heterogéneas nacionalidades que la integran a través del sistema educativo. Por último, la tesis más relevante, tanto por su aceptación como por su significación en el campo literario: el gauchismo de Leopoldo Lugones. También amparado por las instituciones, Lugones llevó a cabo la canonización del Martín Fierro como la obra capital de la literatura argentina, convertida así en epopeya de la nación y mitificando al gaucho como paradigma de lo argentino ${ }^{8}$ : "fácil será hallar en el gaucho el prototipo del argentino actual. Nuestras mejores prendas familiares [...] constituyen rasgos peculiares del tipo gaucho" (1979:50).

A través de un pasado irrecuperable y de un arquetipo popular que el Estado despreció y al que hostigó largamente, el campo cultural elaboró un prototipo de argentinidad que, por supuesto, ni un solo argentino cumplía, pero que al menos resultaba familiar para las familias criollas viejas; es decir, que incluía a aquellos

\footnotetext{
${ }^{6}$ Este sucinto maremágnum se ve enriquecido con una oposición más: la materialismo/espiritualidad que en su momento enunciara Rodó para marcar las diferencias entre los pueblos anglosajones y los hispánicos.

${ }^{7}$ Señalemos también que la situación política de la nación vivirá momentos convulsos y de cambio en estas primeras décadas del siglo XX, empezando por la aprobación en 1912 de la ley Sáenz Peña, que permitirá la llegada del radicalismo yrigoyenista al poder y la consiguiente institución del primer gobierno no oligarca, y, en fin, desembocando en el primer golpe de estado militar en la Historia de la Argentina, encabezado por el general Uriburu en 1930 y apoyado desde las instituciones culturales por Lugones y su tristemente célebre "hora de la espada".

${ }^{8}$ Recordemos que previamente se la consideraba una obra demasiado del gusto de las clases populares, entre las cuales triunfó de forma espectacular, y que, por tanto, no podía representar a las élites cultivadas.
} 
argentinos (aristócratas o no) con antepasados ya radicados allí en el XIX y excluía a las oleadas de inmigrantes italianos, españoles, rusos... ${ }^{9}$ Junto a esto, también se produce otra mitificación, la del campo argentino, esa pampa por la que los supuestos gauchos decimonónicos en teoría vagaban y mateaban libremente. Tenemos, por tanto, un nacionalismo basado en dos ausencias: la temporal y, asimismo, la espacial; pues ya Buenos Aires, sumida en un vertiginoso proceso de cambio y modernización, se había erigido como el centro nuclear e indiscutible del país y la población urbana crecía a ritmo exponencial frente a un campo dependiente que se sumía en el atraso. Esta mitificación del campo será clave en la concepción nacionalista de Borges y uno de sus principales puntos de divergencia con otras corrientes. En resumen, como respuesta a la pérdida de la confianza en el progreso tras la escenificación de su fracaso en la Primera Guerra Mundial, a la inmigración masiva y también por haber carecido de él en el siglo XIX al estar envuelta en los conflictos de su conformación territorial, es en estas primeras décadas del XX cuando se expresa en la Argentina esta corriente neorromántica de tintes herderianos que busca definir y exaltar el espíritu de la nación, entendida como el Volk.

Aunque, aparte de esta discusión en torno al espíritu nacional, hubo otros cambios importantes. Por ejemplo, remarca Sarlo en relación al estatus de los intelectuales y escritores:

Se trata del pasaje de lo que David Viñas denominó "escritores gentlemen" del ochenta a los escritores profesionales; supone un movimiento complicado y muchas veces contradictorio, donde los rasgos de las nuevas relaciones del escritor con la sociedad aparecen contaminados por la supervivencia de formas ideológicas tradicionales. Cuando nos referimos a escritores profesionales [...] lo que define la cuestión no es la forma en que los escritores obtenían sus medios de vida, [...] se trata más bien del proceso de identificación social del escritor: hombres que dejaban de ser políticos y a la vez escritores para pasar a ser escritores que justamente en la práctica de la literatura afirmaban su identidad social (1997: 214-215).

Como hemos podido ver, los escritores saldrán de la acción política directa, pero seguirán participando activamente en cuestiones primordiales para la misma, sobre todo en su tarea de otorgar un nostálgico pasado legitimador, previo a la llegada masiva de inmigrantes, que permita generar en el grueso de la población una identificación nacional argentina. Rompen, de esta forma, también con la tradición literaria modernista, cuyos grandes representantes habían abogado por la autonomía y pureza del arte. Así, sea desde una óptica más conservadora o más reformista, puede considerarse que la mayoría de escritores de la época estuvieron "comprometidos" con el proyecto nacional. Esta colaboración con las instituciones (que en principio contradice el espíritu libre y anarquista de la vanguardia) desemboca en lo que Sarlo denomina el "moderatismo de la vanguardia" argentina:

El moderatismo de la vanguardia argentina es responsable de este fenómeno de verdadera originalidad electiva. La vanguardia es afectada por un obstáculo ideológico que impide su radicalización y promueve varias "ideas fijas" igualmente moderadas: en primer lugar, la convicción de que construir y destruir están implicados, y el rechazo de todo nihilismo; [...]; en segundo lugar, esta vanguardia se preocupa [...] por el trazado de un linaje nacional en el campo de la cultura; también de allí proviene en parte el tono bromista, irónico, pero sustancialmente moderado. [...] El tercer rasgo del moderatismo está en la crítica al filisteísmo burgués [...] realizada en términos exclusivamente estéticos: queda intacto el filisteísmo moral, la hipocresía social, la represión sexual, moral, ideológica (1997: 248-249).

Pasemos ahora a hablar del Borges de dicha etapa, quien, por supuesto, ocupó un puesto de destacada importancia en este panorama. En la década que abarca del 20 al 30, aparte de los tres libros de ensayos que vamos a comentar, Borges publicó también tres libros de poesía y un último volumen de ensayos: Evaristo Carriego, que recoge y depura la mayor parte de sus preocupaciones durante esos años y que, en 1930,

\footnotetext{
${ }^{9}$ Es sintomático a este respecto la insistencia de Borges a lo largo de toda su vida en su pertenencia a un linaje militar que contribuyó a la conformación de la nación argentina, así como su particular reverencia por "los mayores" o su bien conocida e insatisfecha sed por la épica.
} 
marcó, hasta su muerte, el origen de su repertorio ensayístico oficial. Todos estos textos constituyen un horizonte fundacional imprescindible para entender la evolución y la obra posterior del escritor bonaerense; así como para consignar una de las dimensiones de la vanguardia argentina de los años $20^{10}$.

Antes de sumergirnos en los tres volúmenes de ensayos, es importante hacer un apunte acerca de cómo aparecieron estos textos, pues el formato libro solo fue concebido a posteriori. Es en las diferentes revistas, en las que Borges colaboraba asiduamente, donde todos estos escritos salen por primera vez a la luz. Según indica el propio Borges en la "Posdata" de El tamaño de mi esperanza: "Para dejar de leerlo [El tamaño de mi esperanza], no es obligación agenciárselo: basta haberlo ido salteando en las hojas de La Prensa, Nosotros, Valoraciones, Inicial, Proa" (1926: 153). Las revistas fueron el principal medio de difusión cultural de la época y también la plataforma de lanzamiento editorial de sus colaboradores (Proa editó varios de los libros de Borges en estos años ${ }^{11}$ ). Como señala Carlos Walker:

La importancia que en este período tiene la participación del joven Borges en distintas revistas es capital para la construcción de su obra, ya que será precisamente en esa especie de laboratorio abierto donde se den a conocer lo que luego adquirirá, o bien la forma tradicional del libro, o bien la de artículos, notas y poemas dispersos en las distintas publicaciones (2011: 26).

$\mathrm{Y}$, a pesar de que fue en otras donde generalmente aparecieron por primera vez sus ensayos de estos años, la revista fundamental de este periodo fue, sin duda, Martín Fierro, publicación dirigida por Évar Méndez que entre 1924 y 1927 abarca su segunda etapa de existencia y cuyo nombre es paradigma de la vanguardia literaria argentina:

Luego del manifiesto [en el número 4 de Martín Fierro, redactado por Girondo] se incorporaron un contingente de colaboradores regulares, entre los que destacan los nombres de Ricardo Güiraldes, los hermanos González Tunón, Jorge Luis Borges, Norah Lange, Xul Solar, Eduardo Mallea y Macedonio Fernández. La inclusión de esta serie de colaboradores, como efecto de la publicación del manifiesto, fue la que le permitió a la revista instalarse como el eje por el cual circularía una nueva sensibilidad estética, y fue así que comenzó a gestarse la aparición del martinfierrismo como una corriente renovadora de las manifestaciones artístico-literarias de la época. Con el fin de sintetizar se puede decir que el martinfierrismo es un movimiento heterogéneo -lo que dificulta su aprehensión- que encuentra su más claro denominador común en una suerte de propósito vital que repudia abiertamente lo establecido (Walker 2011: 31).

Una vez puntualizado esto, pasemos a revisar brevemente los tres tomos proscritos de ensayos ${ }^{12}$. Podemos comenzar adelantando las cuatro vías que, entrelazándose en forma de red y en gran medida hijas de su contexto, tejerán los intereses de Borges en estos diez años. Lenguaje, literatura, criollismo y metafísica. Todos los textos de esos tres libros tratan de una forma o de otra, individualmente o interconectándolos, esos cuatro temas. No tenemos espacio para hacer una relación y un análisis individual; por lo tanto, trabajaremos en torno a los cuatro temas sugeridos y emplearemos los ensayos para ejemplificar los planteamientos borgeanos ${ }^{13}$.

Entremos por el criollismo, que es, probablemente, el tema más significativo en el contexto de la vanguardia argentina. El criollismo se convirtió en estos años en el término para designar a lo propiamente argentino, en la llave maestra de la argentinidad ${ }^{14}$. Borges, por supuesto, entró en la controversia y a lo largo de diferentes textos quiso contribuir elaborando su propia teoría de lo criollo. Aunque aparece tratado en los

${ }^{10}$ Una maravillosa recreación literaria de la coyuntura y del curso de estos años podemos encontrarla en el Adán Buenosayres de Leopoldo Marechal, una de las plumas preeminentes y más originales de esa época.

${ }^{11}$ Según piensa Juan José Saer (2016) fue, de hecho, su trabajo en las revistas en los 20 y los 30 lo que le ayudó a ensayar la precisión y la sencillez que caracteriza su gran prosa, pues, en la obligación de ser más didáctico, se vio obligado a ir puliendo el barroquismo de sus primeros textos. Esto se apreciaría ya en Historia universal de la infamia.

${ }^{12}$ El único ensayo que rescataría fue el titulado El idioma de los argentinos, sí incluido en posteriores colecciones. También se salvó "Sentirse en muerte", un extraordinario texto del que hablaremos más adelante y que será citado de forma literal, además recordando explícitamente que es un texto de 1928, dentro del ensayo "Nueva refutación del tiempo", incluido en Otras inquisiciones.

${ }^{13}$ Esta labor de análisis textual al detalle de estos libros ya ha sido, además, prolijamente realizada por Víctor Farías en los dos volúmenes que incluimos en la bibliografía.

${ }^{14}$ Para las variaciones en el significado de los términos criollo y criollismo, así como para su relevancia en la historia de la literatura argentina, me remito al capítulo correspondiente en el ya citado libro de Olea Franco. 
tres volúmenes, el libro fundamental para este tema será El tamaño de mi esperanza, en cuyo ensayo homónimo se aportan ya las claves de lo que anda buscando:

A los criollos les quiero hablar: a los hombres que en esta tierra se sienten vivir y morir, no a los que creen que el sol y la luna están en Europa. Tierra de desterrados natos es ésta, de nostalgiosos de lo lejano y ajeno: ellos son los gringos de veras, autorícelo o no su sangre, y con ellos no habla mi pluma. Quiero conversar con los otros, con los muchachos querenciosos y nuestros que no le achican la realidá a este país. [...] No hay leyendas en esta tierra y ni un solo fantasma camina por nuestras calles. Ése es nuestro baldón. [...] Nuestra realidá vital es grandiosa y nuestra realidá pensada es mendiga. Aquí no se ha engendrado ninguna idea que se parezca a mi Buenos Aires. [...] Sin embargo, América es un poema ante nuestros ojos; su ancha geografía deslumbra la imaginación y con el tiempo no han de faltarle versos. [...] Ya Buenos Aires, más que una ciudá, es un país y hay que encontrarle la poesía [...] y la metafísica que con su grandeza se avienen. Ése es el tamaño de mi esperanza, que a todos nos invita a ser dioses y a trabajar en su encarnación. No quiero ni progresismo ni criollismo en la acepción corriente de esas palabras. El primero es un someternos a ser casi norteamericanos o casi europeos [...]; el segundo, que antes fue palabra de acción [...], hoy es palabra de nostalgia (apetencia floja del campo, viaraza de sentirse un poco Moreira). No cabe gran fervor en ninguno de ellos y lo siento por el criollismo. Es verdá que de enancharle la significación a esa voz [...] sería tal vez la más ajustada a mi empresa. Criollismo, pues, pero un criollismo que sea conversador del mundo y del yo, de Dios y de la muerte. A ver si alguien me ayuda a buscarlo (1926: 5-10).

La cita es larga, pero en extremo jugosa; pues en este ensayo, de hecho, se plantean ya, magistralmente, las bases de los cuatro temas que hemos enunciado. Para empezar hay un llamado que reclama a un interlocutor (aquellos a quienes también duele la patria ${ }^{15}$ ) y que se funda en una esperanza de que ambos, escritor y lector, se embarquen en esa aventura de definir lo criollo, aventura basada en coagular en pensamiento la "realidá vital grandiosa" de los argentinos. ¿Cómo lograr esto? Por supuesto, a través de la literatura, a través del canto. No obstante, Borges se aparta del camino más institucional de la vanguardia y renegará del gauchismo rural que, a partir de la visión de Lugones, permeaba el nacionalismo argentino ${ }^{16}$.

En su lugar, con una fina puntería, se centra no en el pasado perdido, sino en la transformación presente del país; es decir, reclama la poetización de su ciudad, de la macrourbe porteña. "Buenos Aires no ha recabado su inmortalización poética", lamenta en Inquisiciones (1925: 28). En este mismo libro, en el ensayo "Buenos Aires", encontramos un ejemplo paradigmático de este proyecto, que siguió otro camino al de Girondo o al de los ultraístas: Borges no se sintió atraído por los tranvías, la luz eléctrica y los automóviles, sino que se traslada a lo que Sarlo (1998) llama "las orillas" para corregir, así, la carencia de leyendas, mitos y fantasmas; sí presentes en la pampa, pero ausentes de la ciudad. De esta forma comienza su recreación y su mitificación del arrabal, del suburbio, "esa indecisión de la urbe donde las casas últimas asumen un carácter temerario como de pordioseros agresivos frente a la enormidad de la absoluta y socavada llanura", por donde "desfilan grandemente los ocasos como maravilladores barcos enhiestos" (1925: 81). Por otra parte, en estos suburbios radica el supuesto origen del tango primitivo ("El flete", "Viento norte", "El caburé") que tanto lo atraerá toda su vida y que, según él, gusta del verdadero sabor de lo heroico (lo criollo en esta época), no como el tango lastimero del que acusa a los inmigrantes italianos ${ }^{17}$. Otro esbozo del suburbio es el delineado

${ }^{15}$ Es interesante señalar que el criollismo borgeano se aleja en parte de los tintes xenófobos que tiñeron ampliamente el nacionalismo argentino. No importa de donde venga la sangre en tanto la preocupación, el dolor y la esperanza sean sinceros, como se apunta en ese ensayo. Con todo, esta actitud es ambivalente, pues en otros lugares también lamenta la extranjerización de la patria, como en "Queja de todo criollo".

${ }^{16}$ Aunque no renegará por completo, pues la pampa, junto con el suburbio, también será un dios. La pampa es un mito demasiado fuerte como para ser fácilmente rechazable. Tengamos también en cuenta que la vía mitificadora vanguardista del gaucho había llegado a su cumbre en 1926 con la publicación de Don Segundo Sombra, de Ricardo Güiraldes, quien dio la sensación de agotar en su excelente novela las posibilidades de este tratamiento; razón de más para que Borges volviera los ojos a la ciudad al encontrarse esa senda cerrada. Un resumen muy interesante de la relación contradictoria que tuvo Borges con la obra de Güiraldes viene desarrollado en el artículo de Christian Fernández que cito en la bibliografía.

${ }^{17}$ De lo consciente y dedicada que es su búsqueda es una prueba el artículo "La pampa y el suburbio son dioses", en El tamaño de mi esperanza, donde hace una breve historia de los cantores del arrabal, historia que termina en él mismo. 
en "Carriego y el sentido del arrabal" (primer artículo que le dedica a este poeta esencial en su obra ${ }^{18}$ ), de $E l$ tamaño de mi esperanza:

Ese anteayer de Palermo no era precisamente idéntico a su hoy. Casi no había casas de alto y detrás de los zaguanes enladrillados y de las balaustraditas parejas, los patios abundaban en cielo, en parras y en muchachas. Había baldíos que hospedaban al cielo y en los atardeceres parecía más sola la luna y una luz con olor a caña fuerte salía de las trastiendas. El barrio era peleador en ese anteayer: se enorgullecía que lo llamaran Tierra del Fuego y que el punzó mitológico del Palermo de San Benito aún perduraba en los cuchillos de los compadres. Había compadritos entonces: hombres de boca soez que se pasaban las horas detrás de un silbido o de un cigarrillo y cuyos distintivos eran la melena escarpada y el pañuelo de seda y los zapatos empinados y el caminar quebrándose y la mirada atropelladora. Era el tiempo clásico de la patota, de los indios. El valor o la simulación del valor era una felicidad (1926: 32-33).

Y un último esbozo, ya para abarcar los tres libros:

Arrabal es todo conventillo del Centro. Arrabal es la esquina última de Uriburu, con el paredón final de la Recoleta y los compadritos amargos en un portón y ese desvalido almacén y la blanqueada hilera de casas bajas, en calmosa esperanza, ignoro si de la revolución social o de un organito. Arrabal son esos huecos barrios vacíos en que suele desordenarse Buenos Aires por el oeste y donde la bandera colorada de los remates [...] va descubriendo América. Arrabal es el rencor obrero en Parque Patricios y el razonamiento de ese rencor en diarios impúdicos. Arrabal es el bien plantado corralón, duro para morir, que persiste por Entre Ríos o por Las Heras y la casita que no se anima a la calle y que detrás de un portón de madera oscura nos resplandece, orillada de un corredor y un patio con plantas. Arrabal es el arrinconado bajo de Núñez con las habitaciones de zinc, y con los puentecitos de tabla sobre el agua deleznada de los zanjones, y con el carro de las varas al aire en el callejón (1928: 165-166).

Esta última cita es importante porque no solo nos traslada geográficamente a las afueras de Buenos Aires (y, más precisamente, al barrio del autor, Palermo, en donde Borges cifra el escenario de su mitología); sino que nos transporta temporalmente al Buenos Aires de su infancia, pues como apunta Olea Franco: "el mito urbano que empieza a fundar en Fervor de Buenos Aires [alude a] una ciudad descrita por medio de elementos marginales que más bien remiten al pasado, por lo que resulta imposible reconocer en ella la imagen bonaerense moderna" (1993: 141). Sin embargo, por esto mismo, también puede señalar que "la singularidad de que la poesía borgeana adopte un tono confesionalista, nostálgico y pasatista solo puede explicarse por el hecho de que en su textualidad se cruzan y entrelazan dos tendencias que tensan su escritura: vanguardismo y criollismo, es decir, renovación estética y tradición" (163). Esto justifica su progresivo alejamiento en estos años de las tendencias ultraístas (y más tarde del de todos los grupos de vanguardia, inclusive el criollista) para llevar a cabo una indagación cada vez más solitaria y personal. "Toda literatura es autobiográfica, finalmente" (1926: 128), postulará en el último ensayo de El tamaño de mi esperanza, preludiando en gran medida esa actitud ${ }^{19}$.

Una vez mitificado el lugar, vendrá el mito del personaje, algunos de cuyos rasgos ya han sido enunciados en la cita de "Carriego y el sentido del arrabal". Si el gaucho fue el personaje mítico de la pampa, su correspondiente en el mítico suburbio borgeano será el compadrito u orillero. Con todo, si el arrabal alcanza ya una mitificación muy profunda en los 20, hará falta esperar hasta 1930, con Evaristo Carriego, para que se formalice y complete la divinización del compadrito, para que se fundan en un todo indisoluble los términos criollo y orillero. Con esto quiero decir: aún no hay una identificación plena y exclusiva entre ambos términos, pues la criolledad es algo a lo que se aspira, no algo definitiva y mitológicamente irrecuperable. No obstante, Borges sí apunta en estos libros el carácter del tipo criollo cuyo epítome será luego el orillero y que más tarde se universalizará a través de la veta épica del culto al coraje. "El criollo, a

\footnotetext{
${ }^{18}$ El artículo de Cristina de la Torre López recogido en la bibliografía resume acertadamente la compleja relación de Borges con la obra de Carriego, quien fue fundamental para la evolución del pensamiento criollista de Borges y, por supuesto, para el posterior libro de ensayos de 1930 con su nombre por título.

${ }^{19}$ Dejo en la bibliografía un interesante artículo de Robin Lefere en tono a esta cuestión.
} 
mi entender, es burlón, suspicaz, desengañado de antemano de todo y tan mal sufridor de la grandiosidad verbal que en poquísimos la perdona y en ninguno la ensalza. [...] Hay que morirse bien, sin demasiado ahínco de quejumbre, sin pretender que el mundo pierde su savia por eso y con alguna burla linda en los labios" (1925: 132, 138).

Con este talante asocia Borges en esta época al personaje de Rosas, a cuya recuperación contribuye en detrimento de la figura de Sarmiento (por ejemplo, en "Queja de todo criollo"). Entre la civilización y la barbarie, se decanta en estos momentos por la segunda, la más próxima al criollismo. Esta actitud se debió a que un nutrido grupo de intelectuales consideraba que el pensamiento liberal progresista predominante tras la batalla de Caseros había destruido el mundo criollo que ellos trataban de rescatar. Rosas, en cambio, "pese a sus fechorías e inútil sangre derramada, fue queridísimo del pueblo" y representa la virilidad, el estoicismo y la parquedad en palabras típica del criollo (1925: 132). En los 20, esas características del caudillo decimonónico encarnarían para Borges en el líder radical Hipólito Yrigoyen, a quien apoyaría durante esa década $^{20}$.

Reiteremos una vez más que todo este proceso de mitificación que estamos estudiando se realiza paralelamente en su obra poética. Sin embargo, como no vamos a entrar en sus poemarios, ilustremos con una cita de Videla de Rivero cómo este programa teórico mitificador de Buenos Aires que estaba llevando a cabo en sus ensayos de los 20 , también lo practicó en la poesía de dicho periodo:

En este contexto surgen los tres libros poéticos borgeanos aparecidos en la década, Fervor de Buenos Aires (1923), Luna de enfrente (1925) y Cuaderno San Martín (1929), que adoptan, por una parte, las técnicas literarias del vanguardismo, aunque solo parcialmente y muy personalizadas. Por otra parte, buscan expresar el alma de Buenos Aires y desde ella el alma argentina. A partir del suburbio, del compadrito, del malevo y de algunos otros símbolos, Borges crea una mitología porteña que -a su vez- sustenta sus teorizaciones sobre el tiempo, sobre la realidad o irrealidad del universo y otras constantes de su mundo literario, ya perfectamente configuradas en sus libros de iniciación (2011: 115).

Por otra parte, la indagación de Borges durante esos años en la literatura y el lenguaje también será uno de sus territorios predilectos. Podemos apuntar en este sentido distintos tipos de ensayos: aquellos que dedica a autores de la tradición europea, aquellos que consagra a autores rioplatenses, aquellos que versan sobre ejercicios y procedimientos literarios técnicos (con especial interés en la metáfora) y aquellos en los que se pregunta por el lenguaje en clave nacionalista. Desgranemos esta lacónica clasificación.

En primer lugar, podemos comentar la tradición "ajena". Dentro de los ensayos dedicados a la literatura europea podemos distinguir aquellos ensayos en los que reseña o trabaja a autores de habla no hispana, básicamente de la tradición inglesa (el Ulises de Joyce, Sir Thomas Browne, Oscar Wilde...) y aquellos en los que bucea en la tradición española. Estos últimos y numerosos ensayos enraízan, por su parte, con una discusión más profunda en torno a la literatura que se estaba produciendo en esos años y que puede resumirse en el rechazo del modernismo y en una primera aceptación del Ultraísmo ${ }^{21}$. Si el Ultraísmo será luego también abandonado por Borges, su postura frente al modernismo y sus "tecniquerías" se mantendrá durante muchos años. El punto de partida es diáfano: rechazo de Góngora, de "su albacea Rubén" y de su encarnación argentina en Lugones; así como del lenguaje vacío, de las palabras vanas que los modernistas habían dejado en los huesos de tanto uso y de tanta rima fácil y forzada. En contraposición, se defiende la figura de Quevedo y sus metáforas alejadas de la pura palabrería, de su trabajo con el concepto, con el sustrato profundo del lenguaje. La metáfora será el recurso más discutido por Borges en estos años (tiene varios artículos dedicados exclusivamente a teorizar sobre ella en estos tres libros), tema del que apuntaremos solamente por razones de espacio el firme rechazo hacia las "imágenes visuales", primero solo hacia las ya manidas metáforas modernistas y luego también, según avanzaban los años 20, incluso a aquellas que él mismo propugnara en su etapa más ultraísta. Esto se orienta hacia una mayor desposesión y reflexión, hacia la búsqueda de imágenes no tan basadas en la sorpresa, sino más próximas a lo que se ha

${ }^{20}$ En relación a las disputas políticas, vamos a dejar de lado, por razones de extensión, toda la controversia Florida-Boedo, aunque su importancia a finales de los 20 y principios de los 30 fue clave en el panorama cultural y literario argentino. Tanto Sarlo como Olea Franco resumen bien esta cuestión.

${ }^{21}$ El posicionamiento respecto al Ultraísmo tiene dos ensayos muy interesantes, los dedicados a Norah Lange y a González Lanuza, donde apunta las características de lo que anduvieron buscando y su inevitable agotamiento. 
dado en llamar una estética de la alusión. ${ }^{22}$ Un último aspecto reseñable respecto a la tradición española serían sus primeras reflexiones acerca del Quijote, una de las grandes obsesiones del argentino a lo largo de toda su vida.

En un segundo lugar, encontramos los ensayos que exploran la función de la literatura en la recuperación de lo criollo; es decir, cuál es la auténtica tradición criolla y cuál es la literatura criollista que se puede hacer en esos momentos. En esta dirección tropezamos con los tres ensayos dedicados en Inquisiciones a escritores de gauchesca (Ascasubi, Ipuche y Silva Valdés), los presentes en El tamaño de mi esperanza ("El Fausto criollo", dedicado a esta obra de Estanislao del Campo; "La tierra cárdena", consagrado a Hudson; el dedicado a Carriego o el que trata a los escritores uruguayos; también la "Queja de todo criollo" es imprescindible) o los ensayos de tema urbano y criollo de El idioma de los argentinos ("El truco", los textos consagrados a Almafuerte, Wilde y Molinari, los ensayos dedicados al tango o el "Hombres pelearon", simiente del posterior "Hombre de la esquina rosada"). En el mismo sentido, el Martín Fierro saltea inevitablemente en numerosas ocasiones los ensayos.

Todas estas referencias no pretenden más que explicitar cómo, en estos años, Borges se preocupó especialmente por indagar en la tradición que se intentaba construir en la Argentina. Y, dentro de sus preferencias, destaca el rechazo al criollismo literario que se regodea en la nostalgia y que se empeña en mostrar deliberadamente el color local (años después vendrá la idea sobre la ausencia de camellos en el Corán). Escribe en "Las coplas acriolladas": "Tomar lo contingente por lo esencial es oscuridá que engendra la muerte y en ella están los que, a fuerza de color local, piensan levantar el arte criollo" (1926: 83). La propuesta de Borges para la literatura criolla se sustenta en el polo opuesto: un criollismo que se saboree en el presente mirando hacia el futuro y que esté basado, no en trazas circunstanciales, sino en una actitud vital profunda y una especial relación con la realidad. Dicha actitud criolla tiene en dos rasgos esenciales: por una parte, aporta al mundo una postura vitalista con "más alegría y un descreimiento especiales"; pero, además, debe ser "conversador[a] del mundo y del yo, de Dios y de la muerte" $(83,10)$. A pesar de todo, esa alegría, que luego comentaremos en relación a la visión de Farías, también se complementa y contradice con una concepción más hosca y melancólica: "La tristura, la inmóvil burlería, la insinuación irónica, he aquí los únicos sentires que un arte criollo puede pronunciar sin dejo forastero" (1925: 135).

Como podemos ver, estas cuestiones sugieren tanteos en lo que Olea Franco (1993) llamará su preferencia por la "estética de la alusión" en detrimento de la "estética de la expresión"; uno de los grandes hallazgos de su literatura posterior. A pesar de todo, las contradicciones en este terreno son demasiado fáciles y Borges también caerá en ellas, como hemos visto en el párrafo anterior, nueva muestra de la tensión que se genera entre la búsqueda estética y la búsqueda nacionalista: "El rechazo de Borges a adoptar un criollismo basado en la nostalgia y en el color local resulta claro como enunciación directa en ciertos momentos de su discurso ensayístico. Sin embargo, más arduo le resulta deshacerse de esa carga en su propia escritura, como parece demostrarlo la recepción de sus contemporáneos" (111).

Todo esto se relaciona, inevitablemente, con una disputa por el lenguaje. El ensayo clave al respecto durante este periodo será el que da título al volumen El idioma de los argentinos ${ }^{23}$. A la hora de erigir un sujeto nacional siempre es imprescindible acordar cuál es el lenguaje de dicho sujeto. Esta fue otra controversia que hizo correr ríos de tinta en la Argentina de la época y de nuevo podemos plantearla a través de dos polos que Borges resume de esta forma:

Dos influencias antagónicas entre sí militan contra un habla argentina. Una es la de quienes imaginan que esa habla ya está prefigurada en el arrabalero de los sainetes; otra es la de los casticistas o españolados que creen en lo cabal del idioma y en la impiedad o inutilidad de su refacción. [...] Dos deliberaciones opuestas, la seudo plebeya y la seudo hispánica, dirigen las escrituras de ahora (1928: 163, 177).

Borges rechazará ambas y ensayará otra definición sustentada en el habla cotidiana: "Equidistante de sus copias [las dos corrientes antes formuladas], el no escrito idioma argentino sigue diciéndonos, el de nuestra

\footnotetext{
${ }^{22}$ Por resumir, podemos indicar que, como apunta Olea Franco, en estos ensayos "priva una actitud escéptica hacia la metáfora, en especial en lo que respecta a su funcionalidad estética" (1993: 170).

${ }^{23}$ Aunque no el único importante: de El tamaño de mi esperanza podríamos nombrar "Invectiva contra el arrabalero" o "El idioma infinito" y de Inquisiciones la "Queja de todo criollo", por ejemplo.
} 
pasión, el de nuestra casa, el de la confianza, el de la conversada amistad". Y la raíz de este lenguaje la cifrará, muy sintomáticamente, en las generaciones anteriores:

Mejor lo hicieron nuestros mayores [Sarmiento, Echevarría, Wilde...]. El tono de su escritura fué el de su voz: su boca no fué la contradicción de su mano. Fueron argentinos con dignidad: su decirse criollos no fué una arrogancia orillera ni un malhumor. Escribieron el dialecto usual de sus días: ni recaer en españoles ni degenerar en malevos fué su apetencia. [...] Hoy esa naturalidad se gastó (176-177).

Esta elección de un lenguaje, en conclusión, nos vuelve a empujar hacia el tema del nacionalismo. No se discute, meramente, una forma de hablar u otra, una mayor o menor corrección lingüística; sino cuál es la forma de expresar el espíritu criollo, la argentinidad. Se trata de encontrar una posición que diste tanto del español peninsular y su hegemonía académica, como del habla de las clases populares argentinas, que tampoco puede ser aceptada por las élites culturales. Por eso, Borges concluye:

Pero la argentinidad debería ser mucho más que una supresión o que un espectáculo. Debería ser una vocación. [...] Nuestra discusión será hispana, pero nuestro verso, nuestro humorismo, ya son de aquí. Lo emotivo [...] es asunto de ellas y lo rige la atmósfera de las palabras, no su significado. [...] Pero nosotros quisiéramos un español dócil y venturoso que se llevara bien con la apasionada condición de nuestros ponientes y con la infinitud de dulzura de nuestros barrios y con el poderío de nuestros veranos y nuestras lluvias y con nuestra pública fe. [...] La esperanza es amiga nuestra y esa plena entonación argentina del castellano es una de las confirmaciones de que nos habla. Escriba cada uno su intimidad y ya la tendremos. Digan el pecho y la imaginación lo que en ellos hay, que no otra astucia filológica se precisa (178-183).

$\mathrm{Si}$, por otra parte, revisamos la escritura, el estilo del argentino en estos tres libros, veremos que lleva a cabo en los ensayos un proceso de trabajo sobre su lenguaje paralelo en gran medida al de las reflexiones que en ellos se desarrolla. Así, a muy grandes rasgos, desde el cierto barroquismo en la expresión (inspirado en la prosa española del XVII, cercano al Quevedo que admiraba durante su época ultraísta) que caracteriza la compleja y engolada expresión de Inquisiciones, pasará, en El tamaño de mi esperanza, hasta un criollismo exacerbado, pleno de argentinismos y con la característica grafía criolla, para finalmente desembocar, en El idioma de los argentinos, en una expresión algo más suave y pulida, que tienta y busca lo criollo pero sin los excesos del libro anterior, inmersa en los inicios del proceso de depuración que caracterizará al Borges futuro. Cada vez más próxima a la prosa de Evaristo Carriego, en definitiva. Plantea al respecto Humerto Rasi:

Los diez o doce primeros años de la producción de Borges revelan a un autor en procura de su estilo, tentado alternativa o simultáneamente por el uso y abuso de cultismos, neologismos y regionalismos. Se percibe con frecuencia un esfuerzo de ser original o una jactancia de escritor joven que exhibe su diestro manejo de la lengua, conocedor de todos sus trucos jergas y matices (1971: 204).

Sin embargo, ya en este último libro comienza a hacerse más patente un cierto recelo con respecto al lenguaje que, en cierta medida, lo apartará por completo de la poesía en los años 30 (al perder la confianza en la representación del mundo a través de la palabra poética) y lo empujará hacia las disquisiciones en torno al lenguaje, centrales en el "Borges universal".

Apuntemos algún aspecto de aquel cuarto tema que, al caracterizar a esta terna de libros, habíamos designado como metafísica. La filosofía, y más precisamente la rama de la metafísica idealista, siempre fue uno de los intereses más destacados del argentino; aunque en la década de los 20 todavía estuviera a unos cuantos años de poder manejar, con suficiente soltura, los aspectos que le interesaron de este campo en aras de construir sus ficciones más célebres. Tanto el repertorio de lecturas que manejó en su juventud, como la correspondencia con Sureda y Abramóvich o su profunda admiración por el Unamuno filósofo y el "metafísico" porteño Macedonio Fernández, ilustran este hecho. Insinúa el propio Borges en "El truco": "Se trasluce que el tiempo es una ficción, por ese pensar. Así, desde los laberintos de cartón pintado del truco, nos hemos acercado a la metafísica: única justificación y finalidad de todos los temas" (1928: 33-34). Además, hay varios textos de esta época que tratan este tema y muestran la incipiente atracción del joven Borges por las quimeras de la realidad, el sujeto y el objeto. Citemos los dos más obvios, ambos en 
Inquisiciones y complementarios en sus planteamientos: "La nadería de la personalidad", que busca cuestionar la noción del yo, del sujeto; y "La encrucijada de Berkeley", que trata de hacer lo mismo con el objeto. Lo expuesto en estos dos artículos será revisitado y reescrito en las décadas siguientes, aunque conviene que recalquemos que Borges fue un fabulista y un especulador, no un filósofo. Su metafísica fue más una excusa estética que un sistema explicativo y coherente.

No obstante, la metafísica más "teórica" de estos dos ensayos que hemos citado, se tiñe con intereses diferentes en otra serie de textos de esta época. Me refiero a lo que la crítica ha llamado la metafísica criollista o "del arrabal" (Farías 1992). Si hemos dicho que durante estos años se busca construir un sujeto nacional y que, para ello, algunos de los hitos imprescindibles son definir el idioma que habla dicho sujeto y cuál es la tradición literaria que lo representa; el siguiente paso es proyectar la trascendencia de dicho sujeto, su esencia, lo que en estas páginas hemos estado llamando el arquetipo de la argentinidad. Hemos visto cómo Borges recorre este camino con el objetivo de penetrar ese espíritu de lo argentino y, por supuesto, lo llevará finalmente hasta los territorios de la metafísica; la cual él mismo reclamaba para nutrir el mito de Buenos Aires en el ensayo "El tamaño de mi esperanza".

Hay dos textos fundamentales a este respecto: "La pampa y el suburbio son dioses", en El tamaño de mi esperanza; y "Sentirse en muerte", en El idioma de los argentinos. "El arrabal ha surgido, dice Borges en 1926, como correlato histórico de la pampa. El gaucho -símbolo pampeano- recibe a su complementario, el compadre -símbolo 'de las orillas"” (1926: 49). A través de la sacralización de esos dos lugares y de los personajes míticos que los pueblan, así como del hallazgo de su música litúrgica, el tango; se elevan realidades comunes a la categoría de símbolos, capaces de colmarse de significaciones que permitan un reconocimiento entre iguales. El tono tal vez más militante de otros textos criollistas adquiere en estos un aliento más profundo y grave, hasta el punto de que es algo irracional, algo casi físico, lo que define al verdadero argentino: "Es indudable que el arrabal y la pampa existen del todo y que los siento abrirse como heridas y me duelen igual" (1928: 23). Es en este sentido que la crítica habla del "criollismo universal" de Borges (Vaccaro, 2015): la consideración de la realidad desde la metafísica permite llevarla hacia un plano superior, pues, finalmente, como apuntara el propio Borges, muy consciente de lo que estaba buscando, el criollismo que propugna debe ser "conversador del mundo y del yo, de Dios y de la muerte" (1926: 10).

Considero que el texto más logrado de estos tres libros es el titulado "Sentirse en muerte". Dice Borges en el prólogo a El idioma de los argentinos, refiriéndose a dicho libro: "Tres direcciones cardinales lo rigen. La primera es un recelo, el lenguaje; la segunda es un misterio y una esperanza, la eternidad; la tercera es una gustación, Buenos Aires. Las dos últimas confluyen en la declaración intitulada 'Sentirse en muerte' " (1928: 8). Que él mismo subraye este texto, nos habla ya de su relevancia: magistral suma y síntesis de muchas de sus preocupaciones de este periodo. De hecho, me parece que en estas escasas páginas puede saborearse con extraño asombro al Borges futuro, al gran Borges de mediados de siglo ${ }^{24}$. Procedimientos técnicos de textos muy posteriores, la dicción precisa para tratar de razonar y enunciar lo inefable (y a la par intensamente físico) en apenas cuatro páginas, abismarse en la historia y sus universales, sentir en el vislumbre inesperado de revelación un tiempo que no desemboca. Más aún, que, en última instancia, este texto haya sido incluido con "Hombres pelearon" (recordemos, simiente del primer cuento de Borges. que será también una de las cumbres de su tratamiento del criollismo literario) bajo el mismo epígrafe "Dos esquinas", nos sugiere una posición privilegiada de ambos textos en el corpus del joven Borges, preludio del fruto que está madurando en la literatura del argentino.

Si ya había puesto en solfa los dos planos físicos de la realidad (sujeto y objeto, en los ensayos de Inquisiciones), ahora cuestiona también el tiempo, la sustancia que da existencia a ambos planos, el "vértice en que se unen la eternidad y el lugar, [que Borges] ve realizarse como una imagen" (Farías, 1994: 324). Pero, además, esta trascendencia tiene como escenario el arrabal porteño, la pobreza cotidiana y dichosa del suburbio; allá en los límites donde Palermo se difumina con la llanura: escenario primario de lo criollo, punto en el que el espacio físico deja de ser sustancia material para volverse sustancia trascendente a través de la percepción del sujeto:

Me sentí muerto, me sentí percibidor abstracto del mundo: indefinido temor imbuido de ciencia que es la mejor claridad de la metafísica. No creí, no, haber remontado las presuntivas aguas del

\footnotetext{
${ }^{24}$ Más aún, podemos reconocerlo de forma explícita, pues, como ya señalamos en otra nota unas páginas más arriba, este texto aparecerá enteramente citado en "Nueva refutación del tiempo", ensayo de Otras inquisiciones. Otro texto que también parece prefigurar intereses y técnicas narrativas posteriores (aunque, en mi opinión, de menor atractivo) podría ser "Historia de los ángeles", en El tamaño de mi esperanza.
} 
Tiempo; más bien me sospeché poseedor del sentido reticente o ausente de la inconcebible palabra eternidad.

Solo después, el sujeto es capaz de esbozar una explicación para su fascinante visión:

El tiempo, si podemos incluir francamente esa identidad, es una delusión: la indisolubilidad de un momento de su aparente ayer y otro de su aparente hoy, basta para desordenarlo. [...] Derivo de antemano esta conclusión: la vida es demasiado pobre para no ser también inmortal. Pero ni siquiera tenemos la seguridad de nuestra pobreza, puesto que el tiempo, fácilmente refutable en lo sensitivo, no lo es también en lo intelectual, de cuya esencia parece inseparable el concepto de sucesión; [...].

por lo que al final todo se reduzca a "la insinuación posible de eternidad de que esa noche no me fue avara" (1928: 150-151). La construcción "metafísica del arrabal" adquiere en este texto su pleno sentido; así como la imagen del suburbio, que, al salirse del plano temporal, alcanza la universalidad.

Usemos este texto, donde una de las significaciones de esa experiencia "era ciertamente de dicha" (149), para enlazar con un último apunte. Señala Farías que en estos libros se muestran aspectos clave del joven Borges que el Borges maduro quiso hacer desaparecer de su figura de autor; razón por la cual prohibió la reedición de estos volúmenes:

La obra proscrita del joven Borges contenía, vivaz y brillante, consecuente y profético, al antiBorges del Borges que todos conocíamos; [con] una concepción de la vida diametralmente opuesta al Borges oficializado, [...] [con] una visión espontánea y transparente de la vida real y cotidiana. La vida como virtual positividad sencilla y simple; tarea grata, si yo la hago tal (1994: 18-19).

El humanismo vitalista de este joven Borges puede, de forma clara, irse rastreando en varios de los textos. Su búsqueda de la felicidad, de lo grato del mundo, la creencia típicamente juvenil de que el mundo puede estar bien hecho y de que la esperanza en el porvenir es una quimera a la que merece la pena aspirar: "Suele suponerse que la literatura ya ha dicho las palabras esenciales de nuestro vivir y sólo puede innovar en las gramatiquerías y en las metáforas. Me atrevo a aseverar lo contrario: sobran laboriosidades minúsculas y faltan presentaciones válidas de lo eterno: de la felicidad, de la muerte, de la amistad" (1928: 51). Dos últimas citas para ilustrar esto, ahora procedentes de El tamaño de mi esperanza:

Grato es el gesto que en una brusca soledad resplandece, grata es la voz antigua que denuncia nuestra comunidad con los hombres y cuyo gusto (como el de cualquier amistad) es el de sentirnos iguales y aptos de esa manera para que nos perdonen, amen y sufran. Graves y eternas son las hondas trivialidades del enamorarse, de caminar, de morir (1926: 74).

Sigue pareciéndome que la dicha es más poetizable que el infortunio y que ser feliz no es cualidad menos plausible que la de ser genial (14).

$* * *$

Cerremos con algunas de las reflexiones que se puedan extraer de lo expuesto en estas páginas. La más evidente es que una comprensión completa de la obra de Borges es imposible sin tener en cuenta estos tres libros de ensayos de los años 20. Primero, porque correríamos el peligro de caer en el adanismo al pensar que, formalmente, su primera tentativa en el mundo del ensayo fue Evaristo Carriego, un libro bastante maduro ya para 1930. Así, si solo tuviéramos en cuenta la Obra completa autorizada por él mismo, el panorama sería el de un poeta que escribe en verso durante diez años y, luego, abandona la poesía, decide pasarse a meditar en prosa sobre un poeta menor muerto veinte años atrás $\mathrm{y}$, posteriormente, dispone lanzarse al cultivo de la narrativa. Sin embargo, como hemos visto, esto no es ni mucho menos así: hasta Evaristo Carriego hay un largo camino de trabajo e indagación, de tanteos estilísticos y temáticos, de preocupaciones y candentes discusiones en el contexto histórico en el que escribía. De hecho, en cierta medida, podemos postular el volumen sobre Carriego como una síntesis de sus principales intereses de los años 20; pero, para llegar hasta allí, hubo un largo camino detrás. Además, en estos libros, no solo se nos abren las puertas del ensayo, sino que también se nos muestran las primeras pinceladas de su prosa, la 
evolución estilística de la misma (que muestra una progresiva y vacilante tendencia hacia la depuración después de la etapa más criollista, el comienzo del pasaje de la "estética de la expresión" a la "estética de la alusión") e incluso esa primera tentativa de protorrelato que supone "Hombres pelearon". Estos tres libros, en definitiva, hacen de puente e interrelacionan de forma lógica las diferentes obras que durante mucho tiempo conformaron el canon oficial del Borges joven.

Hemos señalado también que en estos volúmenes hay cuatro temas recurrentes que recogen y desarrollan sus preocupaciones durante esa década: el lenguaje, la tradición literaria, el criollismo y la metafísica. Esta comprobación nos permite apreciar el continuum entre el joven y el viejo Borges, las afinidades que los ligan y las diferencias que los separan, y descubrir cómo algunos de los aspectos que le granjearon la fama décadas después ya están esbozados o postulados en estas primeras obras juveniles. Por el contrario, tanto la faceta humanista y vitalista que señala Farías como la dimensión más nacionalista desaparecen en sus obras posteriores y son borradas por completo del mapa si no tenemos en cuenta estos tres libros. Podemos aducir que Evaristo Carriego recoge esta veta del criollismo, lo cual es cierto; sin embargo, el radicalismo nacionalista queda en este volumen suavizado a través de una concepción más universalista del criollismo, más tendente hacia la metafísica y hacia lo que posteriormente llamará el "elemental sabor de lo heroico" que hacia el nacionalismo militante. Este olvido voluntario puede entenderse si se revisa el contexto histórico y vital de los siguientes años del argentino. Ya para la redacción de Evaristo Carriego, Borges ha dejado de apoyar al caudillo radical Hipólito Yrigoyen. Luego vendrá el golpe de estado de 1930 y la proliferación de gobiernos fascistas a lo largo y ancho del globo y, finalmente, la Segunda Guerra Mundial en Europa y la victoria de Perón en Argentina, cuyo populismo será comparado por Borges al de Hitler. El nacionalismo deja de tener que ver, como en los años 20, con la búsqueda de las esencias, de la trascendencia metafísica de los pueblos, para teñirse de pura realidad material y de violencia. La situación personal de Borges durante el gobierno de Perón es, asimismo, bien conocida y su posterior posicionamiento ideológico con respecto al peronismo también. Ese progresivo viraje hacia el conservadurismo puede ser una de las principales razones por las que trató de eliminar el ensayismo de la época en que fue afín al radicalismo nacionalista de izquierdas.

En definitiva, si bien es cierto que estos primeros textos todavía no están del todo maduros y que este Borges no es tan genial, perspicaz ni profundo como el de su época de esplendor, en estos tres libros se recogen algunos aspectos muy interesantes e imprescindibles para entender al Borges posterior. Por otra parte, es lógico que haya primado la dimensión universal del escritor bonaerense, pero si no tenemos en cuenta lo profundamente que enraíza su literatura en el contexto y la tradición argentinos, cuya faceta más radical aparece probablemente en estos libros, estaremos emborronando el cuadro y dejándonos engañar por la figura de autor que el propio Borges trató de construir con tanto ahínco a lo largo de 50 años. El personaje Borges desplazaría a lo que el propio Borges dejó plasmado en sus textos.

\section{Referencias bibliográficas}

Borges, Jorge Luis (1925). Inquisiciones: Buenos Aires: Proa.

Borges, Jorge Luis (1926). El tamaño de mi esperanza. Buenos Aires: Proa.

Borges, Jorge Luis (1928). El idioma de los argentinos. Buenos Aires: M. Gleizer.

De la Torre López, Cristina (2007), "Raíces ideológicas y culturales del símbolo del arrabal en las primeras obras de Borges", Arrabal (5-6), pp. 105-114.

Farías, Víctor (1992). La metafísica del arrabal. El tamaño de mi esperanza: un libro desconocido de Jorge Luis Borges. Madrid: Anaya \& Mario Muchnik.

Farías, Víctor (1994). Las actas secretas. Inquisiciones y El idioma de los argentinos, los otros libros proscritos de Jorge Luis Borges. Madrid: Anaya \& Mario Muchnik.

Fernández, Christian (1999), "El tamaño de la influencia: Gauchesca, criollismo y nación: Sarmiento y Güiraldes leídos por Borges", Revista de Literatura Hispánica (49-50), Spring-Autumn, pp. 9-25.

Humberto Rasi, Mario (1971). Lo argentino en la obra de Jorge Luis Borges. Tesis Doctoral. Stanford University.

Lefere, Robin (2007), "Borges entre autorretrato y automitografía", Nueva Revista de Filología Hispánica, vol. LV, nº 2, julio-diciembre, pp. 542-547.

Lugones, Leopoldo (1979). El payador y Antología de poesía y prosa. Sel. Guillermo Ara. Caracas: Biblioteca Ayacucho.

Olea Franco, Rafael (1993). El otro Borges. El primer Borges, Buenos Aires, FCE.

Saer, Juan José (2016), “Borges francófobo”, en El concepto de ficción. Barcelona: Rayo Verde, pp. 39-47.

Sarlo, Beatriz (1997), "Vanguardia y criollismo: La aventura de Martín Fierro", en Carlos Altamirano y Beatriz Sarlo. Ensayos argentinos. De Sarmiento a la Vanguardia. Buenos Aires: Ariel, pp. 211-255.

Sarlo, Beatriz (1998). Borges, un escritor en las orillas. Buenos Aires: Ariel. 
Vaccaro, Santo Gabriel (2015), "El criollismo universal en Jorge Luis Borges: Apuntes sobre lengua y literatura", Itinerários, Araraquara, $\mathrm{n}^{\circ}$ 41, jul/dez. pp. 53-67.

Videla de Rivero, Gloria (2011), "La dirección criollista de la vanguardia", en Direcciones del vanguardismo hispanoamericano. Mendoza: EDIUNC, pp. 105-118.

Walker, Carlos (2011), “Jorge Luis Borges: De Martín Fierro a Sur”, Iberoamericana, XI, 41, pp. 25-42. 